\section{Manejo farmacológico coadyuvante al tratamiento endodóntico}

Bobbio-Abad S, Ghersi-Miranda HD, Hernández-Añaños JF. Manejo farmacológico coadyuvante al tratamiento endodóntico. Rev Estomatol Herediana. 2011; 21(1):110-115.

RESUMEN

Durante la terapia endodóntica, el dolor, inflamación e infección son unos de los principales motivos de consulta que afronta el endodoncista. El control de estos signos y síntomas pueden ser tratados mediante la acción de procedimientos locales, medicación local o tópica, así como de coadyudantes farmacológicos.

Palabras clave: INFLAMACIÓN / INFECCIÓN / FARMACOLOGÍA / DOLOR.

Use of pharmacological agent in endodontic treatment

ABSTRACT

During endodontic therapy, pain, inflammation and infection are among the main chief complaints. The control of these signs and symptoms can be managed by the action of local procedures, local medication topical as well as pharmacological.

Key words: INFLAMMATION / INFECTION / PHARMACOLOGY / PAIN.

Sandra Bobbio Abad ${ }^{1}$ Hugo Dante Ghersi Miranda ${ }^{2}$ Juan Felipe Hernández Añaños ${ }^{3}$

'Residente del Programa de Especialización en

Endodoncia.
2Docente del Departamento Académico de Medicina 'Docente del Departamento Acad
y Cirugía bucal y maxilofacial.

'Docente del Departamento Académico de Clínica Estomatológica.

Facultad de Estomatología. Universidad Peruana Cayetano Heredia

\title{
Correspondencia
}

Sandra Bobbio Abad

El cortijo 473 casa 18 - Lima 33, Perú.

Teléfono: 4361418/993579414

e-mail: Sandra.bobbio @ hotmail.com

Recibido :5 de abril de 2011

Aceptado : 10 de junio de 2011

\section{Introducción}

Durante la terapia endodóntica, el dolor, inflamación e infección son unos de los principales motivos de consulta que afronta el endodoncista. Un desbridamiento inadecuado, sobreinstrumentación, presencia de conductos radiculares no tratados, la existencia de contactos prematuros, una restauración provisional mal adaptada o factores locales propios del paciente son algunas de las causas que podrían originar sintomatología dolorosa y/o infecciosa (1-3).

El control de estos signos y síntomas pueden ser tratados mediante la acción de procedimientos locales, medicación local o tópica, y coadyudantes farmacológicos tales como analgésicos y/o antibióticos para el control de las lagias e infecciones odontogénicas (1-5).

El uso de fármacos en Endodoncia es un tema importante y controversial. Algunas escuelas promueven el uso de sólo medicación tópica, otras escuelas justifican la medicación sistémica e incluso existen las cuales no indican ni medicación sistémica ni tópica (4).

Para toda prescripción de un fármaco se debe evaluar completamente al paciente, teniendo en cuen- ta su historia clínica médica general y estomatológica donde se observará sus signos y síntomas (6-8), lo que nos permitirá arribar al origen del dolor e inflamación y por lo tanto a la farmacoterapia adecuada. Hay diferencia en la farmacoterapia para el dolor e inflamación por un trauma, infección o neuralgia. Como endodoncistas nos enfrentamos a diferentes casos de pulpitis irreversibles, necrosis pulpares e infecciones, por ello el objetivo de nuestro tratamiento endodóntico es el de eliminar el factor etiológico (la causa) del dolor e inflamación, basándonos en desinfección, conformación y sellado de los conductos radiculares (6-9).

\section{Principios farmacológicos}

Los principios farmacológicos están basados en dos conceptos esenciales.

\section{Farmacocinética}

Estudia los procesos por los cuales un fármaco puede ser asimilado por el organismo, resumido por las siglas LADME (Liberación, Absorción, Distribución, Metabolismo Excreción del fármaco) (5-7).

Farmacodinámica
Relacionada con efectos del fármaco en el organismo. Estudia la relación entre la concentración del fármaco y sus efectos bioquímicos, fisiológicos y los mecanismos por los que producen estos efectos (4-6).

\section{Origen del dolor}

Es importante establecer, desde un inicio, que la única respuesta clínica de la pulpa dentaria frente a los diferentes estímulos es el dolor (1014).

\section{Dolor dentinario}

Cuando el contenido de los túbulos dentinarios es excitado lo suficiente como para incluir la capa de células odontoblásticas, las fibras A-delta responderán inmediatamente generando la sensibilidad dentinaria o dolor dentinario. Estos síntomas son dolor agudo que desaparece rápidamente al cesar el estímulo (14).

\section{Dolor pulpar}

Un irritante externo de suficiente magnitud o duración inicia un proceso de inflamatorio pudiendo dañar a la pulpa dental. La respuesta inflamatoria determinará si el daño puede o no ser reparado. El aumento en la presión del tejido intrapulpar, 
es el estímulo que excita a los nervios sensoriales de la pulpa produciendo la odontalgia intensa (14).

Cuando el proceso inflamatorio se encuentra establecido, las fibras A-delta responden exageradamente a los estímulos, especialmente a los térmicos. Cuando las fibras A-delta son dañadas, el dolor persiste pero es percibido como un dolor sordo, que es producido por la estimulación de las fibras C. Con el aumento de la inflamación en la pulpa dental, las fibras $\mathrm{C}$ se convierten en la única estructura capaz de producir dolor. El dolor que empezó como un dolor de corta duración, puede mantenerse o escalar hacia un dolor intenso, prolongado, palpitante y constante. El dolor es entonces difuso y puede referirse a sitios distantes o a otros dientes. Ocasionalmente la vasculatura pulpar responde al frío produciéndose vasoconstricción que disminuye la presión intrapulpar y momentáneamente se produce alivio del dolor. Esta característica es indicativa y diagnóstica de necrosis pulpar (14).

Ingle y Glicks clasifican al dolor pulpar agudo en incipiente, moderado y avanzado:

- Incipiente o leve: En este caso existe una molesta leve donde el paciente está vagamente consciente de cuál es el diente que le molesta, pero no existe un verdadero dolor dental.

- Moderado: En este caso existe un verdadero dolor dental pero el paciente es capaz de tolerarlo. Es difuso, irradiado y prolongado, lo cual lo diferencia de la sensibilidad dentinaria. Su persistencia puede ser por minutos, horas o días. Este dolor puede precipitarse espontáneamente, particularmente con cualquier acto que eleve la presión arterial de la cabeza, o al comer.
- Avanzado o severo: En este caso el paciente experimenta un dolor intenso, agudo que se alivia con agua fría, ya que este método reduce la presión intrapulpar que se encuentra elevada por el proceso inflamatorio.

Para Bender, un dolor pulpar severo es usualmente indicativo de necrosis por licuefacción que eleva la presión intrapulpar a $34,5 \mathrm{~mm} / \mathrm{Hg}$, siendo la presión en una pulpa sana de $10 \mathrm{~mm} / \mathrm{Hg}$. Generalmente esta necrosis está acompañando a una pulpitis parcial crónica. La severidad del dolor disminuye cuando el es una necrosis pulpar total. Concluyendo, cuando un paciente presenta dolor pulpar moderado o severo, la pulpa se encuentra en un estado de inflamación irreversible y el tratamiento de conductos o la extracción está indicada. Sin embar-

\section{Manejo farmacológico de las algias en endodoncia}

DOLOR LEVE por casos de sobreinstrumentación, irritación de tejidos periapicales o dolor post tratamiento (14-16).

Los medicamentos de elección para estos casos son:

\begin{tabular}{ll}
\hline \multicolumn{1}{c}{ ACETAMINOFEN } & \multicolumn{1}{c}{ CLONIXINATO DE LISINA } \\
\hline Analgésico no esteriodeo, & Analgésico y antiinflamatorio no \\
antipirético. & esterioideo (AINES). \\
Acción: se desconoce. & Acción: inhibe la enzima \\
No causa daño gastrointestinal & prostaglandina sintetasa, \\
Dosis: $500 \mathrm{mg}$. c/8hrs - hasta & responsable de la síntesis de \\
4gr/día. & prostaglandinas. \\
& Dosis: 125 mg. c/8hrs. \\
\hline
\end{tabular}

DOLOR MODERADO por casos de sobreinstrumentación, irritación de tejidos periapicales, accidentes de tipo endodóntico o dolor post tratamiento.

Los medicamentos de elección para estos casos son:

AINES que se caracterizan por su acción analgésica, antiinflamatoria, antipirética y antiagregante plaquetario, inhibiendo a la cicloxigenasa (COX 2) $(16,17)$.

\begin{tabular}{ll}
\hline \multicolumn{1}{c}{ IBUPROFENO } & \multicolumn{1}{c}{ AC. ACETIL SALICILICO } \\
\hline Derivado del acído Propinóico. & Dosis: 325 a $650 \mathrm{mg}$. c/8hrs. \\
Dosis: $400 \mathrm{mg}$ c/8hrs. & $\begin{array}{l}\text { Prohibido en paciente con úlcera } \\
\text { péptica. }\end{array}$ \\
\hline
\end{tabular}


DOLOR SEVERO, por casos de procesos agudos, lo recomendable en primer lugar es la terapia endodóntica, empezando por una apertura cameral y/o exéresis pulpar.

\begin{tabular}{ll}
\hline \multicolumn{1}{c}{ CLORHIDRATO DE } & \multicolumn{1}{c}{ CLORHIDRATO DE } \\
\multicolumn{1}{c}{ TRAMADOL } & TRAMADOL + PARACETAMOL \\
\hline Dosis: $50 \mathrm{mg}$ c/8hrs. & Dosis: clorhidrato de tramadol \\
Dosis máxima: 400mg/día. & 37,5mg+ Paracetamol 325mg. \\
Efectos adversos: cefalea, náusea, & $\begin{array}{l}\text { Dosis máxima: } 4 \text { comprimidos/día. } \\
\text { vómitos, mareo, somnolencia. }\end{array}$ \\
& $\begin{array}{l}\text { Reduce los efectos adversos dados } \\
\text { por el clorhidrato de tramadol. }\end{array}$ \\
\hline
\end{tabular}

\section{Inflamación en endodoncia}

Una inflamación pulpar o denominada pulpitis irreversible puede ser aguda, subaguda (exacerbación leve de una pulpitis crónica) o crónica.

La inflamación aguda es sintomática de respuesta brusca y de corta duración, donde existe presencia de neutrófilos y polimorfos nucleares.

Debemos tener en cuenta que la inflamación es una reacción fisiológica, cuyo pico máximo se alcanza de 48 a 72 hrs.

La inflamación crónica es una respuesta que dura varios días, en la que existe proliferación de fibroblastos y del endotelio vascular así como un influjo de las llamadas células inflamatorias crónicas (linfocitos, células plasmáticas y macrófagos) generalmente es asintomática.

Una inflamación pulpar progresiva y cada vez más intensa puede dar lugar a una lesión perirradicular (alrededor de la raíz) inicial, como consecuencia de la interacción de las bacterias y sus productos con los mecanismos de defensa del tejido pulpar.

\section{Manejo farmacológico de la in- flamación en endodoncia}

En casos de inflamación de origen pulpar tanto aguda como crónica es recomendable básicamente el tratamiento de conductos, que pue- de ir acompañado de algún antiinflamatorio (AINES) como el IBUPROFENO, mencionado anteriormente $(16,17)$.

Obersztyn et al. (18) refieren que los corticoides han sido ampliamente usados en tratamientos de pulpitis irreversible. Holland (19) (1996) demostró que la dexametasona de forma sistémica, redujo el grado de inflamación periapical con más eficacia, pero no eliminó la inflamación por lo cual el estudio nos indica que la eliminación de la inflamación se da por el tratamiento de conductos propiamente dicho.

En casos con inflamación aguda, reagudización o una periodontitis apical aguda donde se produce una inflamación de los tejidos periapicales dando lugar a una hiperemia y vasodilatación con exudado de líquido e infiltración leucocitaria, aumenta la presión tisular, el exudado y la infiltración celular, ocasionan la distensión de las fibras del ligamento periodontal originando dolor e inflamación, se puede administrar un corticoesteroide como: DEXAMETASONA de $4 \mathrm{mg}$ c/8hrs x 12 días. (VO), con dosis máxima de 8mg/día (18-22).

\section{Infecciones de origen pulpar}

A pesar de la protección natural que posee la pulpa, algunas bacterias pueden invadirla. Normalmen- te son fácilmente fagocitadas y eliminadas por el sistema de defensa de los tejidos mesenquimatosos sanos. Cuando la protección se rompe, la pulpa puede ser infectada. La infección pulpar se puede producir por varías vías: a través de los túbulos dentinarios (por una cavidad abierta expuesta por caries, grietas, traumatismos o intervenciones dentales), a través de una bolsa gingival profunda (por invasión de los canales laterales o accesorios o el forámen apical), propagación de una infección periapical de un diente adyacente infectado o por vía hematógena (anacoresis) $(1,2,4)$.

La composición microbiana de un conducto radicular infectado se determina por la ruta que toma la bacteria para acceder al canal, y el número y la calidad de los factores ecológicos. La probabilidad de encontrar una gran variedad de especies bacterianas orales es mayor en caso de lesiones abiertas que si la infección tiene lugar a través de mecanismos selectivos.

Las infecciones de origen endodóntico, en la mayoría de los casos están asociadas a caries que degeneran en lesiones pulpares sépticas y que evolucionan al periápice y a los tejidos adyacentes $(23,24)$.

Clínicamente estos fenómenos se traducen en un edema leve, dolor, rubor y calor. Posteriormente si el proceso infecioso es más agresivo puede observase celulitis, donde el edema aumenta, deformando los tejidos blandos adyacentes a la pieza dentaria, trismus y picos febriles en algunos casos, sin formación aún de exudado purulento. Posteriormente se forma el absceso propiamente dicho que tiende al drenaje espontáneo por la vía de menor resistencia.

\section{Manejo antimicrobiano de las in- fecciones de origen pulpar de}




\section{acuerdo a la clasificacion}

Dentro de la terapia endodóntica utilizada en el manejo de la infecciones pulpares y periapicales, se tiene como premisa fundamental la la limpieza, desinfección y contorneo de los conductos radiculares y la medicación antibiótica como coadyuvante. El tiempo de tratamiento farmacológico depende de la evolución clínica (25).

El propósito principal de la administración de un antibiótico en estos casos es el de contribuir con la respuesta defensiva del hospedero, limitando la diseminación de la infección, localizandola para ayudar a la resolución de los síntomas (2628).

Plantear una terapéutica antibiótica en procesos infecciosos de la cavidad oral no es fácil, debido a múltiples variables a tener en consideración como: concentración bacteriostática o bactericida a nivel tisular en la zona de la infección. Las infecciones de origen endodóntico son de carácter polimicrobiano (producidas simultáneamente por géneros, especies y cepas distintas) y mixtas. Esto obliga a planificar el tratamiento antibiótico para cubrir estos posibles y múltiples agentes etiológicos. Para planificar la terapéutica antibiótica se deben conocer el mayor y el más común número de patógenos implicados, así como su susceptibilidad in vitro $(29,30)$. Los antibióticos más utilizados en el manejo de las infecciones de origen endodóntico son: la Penicilina Natural, Amoxicilina, Amoxicilina/Ácido Clavulánico, Clindamicina, Cefalosporina de primera generación, Quinolonas y Macrólidos.

El tiempo de administración de ATB dependerá de la evolución del paciente, no excediendo generalmente de los 5 a 7 dias, de lo contrario se debe revaluar el caso.

\section{Conclusiones}

Para medicar un fármaco tenemos que conocer no solo la historia clínica médica completa del paciente, antecedentes, alergias, enfermedades previas. Conocer la farmacocinética, farmacodinámica y espectro microbiano del fármaco elegido, para lograr la acción desea-

\section{da (31-34).}

Los pasos a seguir para los problemas de origen pulpar son los siguientes

Proceso inflamatorio doloroso: eliminación directa de los irritantes microbianos (exéresis pulpar) o el drenaje.

El fármaco con efectos analgésico y antiinflamatorio más recomendado es el Ibuprofeno.

Alérgicos a los Aines se limita a tratamiento con Paracetamol en dolores leves y tramadol + Paracetamol en caso de dolores moderados o severos.

Se indica Dexametasona 8mg vía oral solo en procedimientos cruentos.

No indicar dexametasona en casos de infecciones, o condiciones sistémicas que comprometan el estado inmune del paciente, solo usar como tratamiento antiinflamatorio pre y post operatorio.

La dexametasona reduce la inflamación periapical no la eliminan.

El ibuprofeno como analgésico antiinflamatorio en tratamientos quirúrgicos apicales es el tratamiento farmacológico recomendado.

\begin{tabular}{|c|c|c|c|c|c|}
\hline ATB & $\begin{array}{c}\text { Bacterias } \\
\text { suceptibles }\end{array}$ & Acción & Indicaciones & $\begin{array}{l}\text { Contraindica } \\
\text { ciones }\end{array}$ & Dosis/tiempo \\
\hline Amoxicilina & Gram + & Bactericida & $\begin{array}{l}\text { Procesos } \\
\text { infecciosos } \\
\text { leves }\end{array}$ & Alergia PNC & $\begin{array}{l}\text { 500mg 1c/8hrs x } \\
7 \text { d. (Adulto) } \\
\text { 50mg/ kg.( Niño) }\end{array}$ \\
\hline Clindamicina & Gram - & $\begin{array}{l}\text { Bactericida y } \\
\text { bacteriostático }\end{array}$ & $\begin{array}{l}\text { Procesos } \\
\text { infecciosos } \\
\text { leves- } \\
\text { moderados- } \\
\text { severos }\end{array}$ & $\begin{array}{l}\text { Colitis } \\
\text { pseudo- } \\
\text { membranosa }\end{array}$ & $\begin{array}{l}\text { 300mg 1c/8hrs } \\
\text { x7dias (vo) } \\
600 \mathrm{mg} \text { (im- adul.) } \\
\text { 20mg /kg (Niño) }\end{array}$ \\
\hline $\begin{array}{l}\text { Amoxicilina + } \\
\text { Metronidazol }\end{array}$ & $\begin{array}{l}\text { Gram+ } \\
\text { anaerobios }\end{array}$ & $\begin{array}{l}\text { Bactericida } \\
\text { Bacteroides }\end{array}$ & $\begin{array}{l}\text { Pacientes con } \\
\text { enfermedades } \\
\text { sistémicas no } \\
\text { controladas y } \\
\text { procesos } \\
\text { infecciosos } \\
\text { severos }\end{array}$ & $\begin{array}{l}\text { Colitis } \\
\text { pseudo- } \\
\text { membranosa. } \\
\text { Alergia PNC }\end{array}$ & $\begin{array}{l}500 \mathrm{mg}+250 \mathrm{mg} 1 \\
\text { cap. cada } 8 \text { horas } \\
\text { por } 7 \text { días. }\end{array}$ \\
\hline $\begin{array}{l}\text { Amoxicilina+Ac. } \\
\text { Clavulámico }\end{array}$ & $\begin{array}{l}\text { Gram +, - } \\
\text { beta- } \\
\text { lactamosa }\end{array}$ & Bactericida & $\begin{array}{l}\text { Procesos } \\
\text { infecciosos } \\
\text { severos }\end{array}$ & Alergia PNC & $\begin{array}{l}500 \mathrm{mg}+ \\
125 \mathrm{mg} \cdot 1 \mathrm{c} / 8 \mathrm{hrs} \mathrm{x} \\
7 \text { días. }\end{array}$ \\
\hline
\end{tabular}


La clindamicina se indica a menudo en infecciones endodónticas, como segunda elección. Tienen un buen y concentración en el tejido óseo.

Si la lesión apical compromete la cavidad sinusal provocando una sinusitis maxilar aguda o crónica se inicia terapia con Amoxicilina 875mg + Ac.Clavulámico 125mg c/8 horas de 5 a 7 días, de acuerdo a evolución.

\section{Referencias bibliográficas}

1. Cohen S, Buns R. Vías de la pulpa. 8a ed. Madrid: editorial Elseiver España; 2001.

2. Ingle J, Backland L. Endodontic. 5a ed. London: Mcgraw Hill; 2002.

3. Soares I, Godlberg F. Endodoncia: técnica y fundamentos. 1ra ed. Madrid: Editorial médica panamericana; 2002.

4. Terézhalmy GT. Farmacodontología. Clínicas Odontológicas de Norteamérica - Vol.4. Pennsylvania: Editorial interamericana; 1994.

5. Bascones A. Farmacología y terapéutica. Clínicas Odontológicas de Norteamérica - Vol.3. Madrid: Editorial interamericana; 1984.

6. Shubhad N, Flood K, Paranjothi S. El manual Washington de terapéutica médica. 30ma ed. Barcelona: Mc Graw Hill; 2001.

7. Katzung BG. Farmacología básica y clínica. 9a ed. San Francisco: editorial manual moderno; 2001.

8. Gutman J, Dumsha T, Lovdahl P. Soluciones en problemas en endodoncia, prevención, identificación y tratamiento. 4ta ed. Madrid: Elsevier España; 2007.

9. Caviedes-Bucheli J, Rojas P, Escalona M, Estrada A, Sandoval C, Rivero C, Lombana
N, Muñoz HR. The effect of different vasoconstrictors and local anesthetic solutions on substance $P$ expression in human dental pulp. J Endod. 2009; 35(5):631-3.

10. Holstein A, Hargreaves KM, Neiderman R. Evaluation of NSAIDs for treating postendodontic pain. A systematic review. Endod Topics. 2002; 3(1):3-13.

11. Ali A, Roig M. Manual de endodoncia. Parte 15. Dolor postoperatorio en endodoncia. Rev Oper Dent Endod 2008;7:116.

12.Doroschak AM, Bowles WR, Hargreaves KM. Evaluation of the combination of flurbiprofen and tramadol for management of endodontic pain. J Endod. 1999; 25(10):660-3.

13. Thomson. Vademécum. 19a ed. Lima: Editorial Thomson; 2007.

14. Khan AA, Dionne RA. COX-2 inhibitors for endodontic pain. Endod Topics. 2002; 3(1):31-40.

15. Hutchins M, Housholder G, Suchina J, Rittman B, Rittman G, Montgomery E. Comparison of acetaminophen, ibuprofen, and nabumetone therapy in rats with pulpal pathosis. J Endod. 1999; 25(12):804-6.

16. Mickel AK, Wright AP, Chogle S, Jones JJ, Kantorovich I, Curd F. An analysis of current analgesic preferences for endodontic pain management. J Endod. 2006; 32(12):1146-54.

17. Kwan P, Laskin D. Manual clínico de cirugía oral y maxilofacial. 3a ed. Caracas: Editorial Amolca; 2003.

18. Obersztyn A, Jedrzejczyk J, Smiechowska W. Application of lyophilized dentin chips, mixed with prednisolone and neomycin, on infected rat incisor pulp. $\mathrm{J}$
Dent Res. 1968; 47(3):374-80.

19. Holland GR. Steroids reduce the periapical inflammatory and neural changes after pulpectomy. J Endod. 1996; 22(9):455-8.

20.Krasner P, Jackson E. Management of posttreatment endodontic pain with oral dexamethasone: a double-blind study. Oral Surg Oral Med Oral Pathol. 1986; 62(2):187-90.

21. Marshall JG. Consideration of steroids for endodontic pain. Endod Topics. 2002; 3(1):41-51.

22. Nobuhara WK, Carnes DL, Gilles JA. Anti-inflammatory effects of dexamethasone on periapical tissues following endodontic overinstrumentation. J Endod. 1993; 19(10):501-7.

23. Torabinejad M, Dorn SO, Eleazer PD, Frankson M, Jouhari B, Mullin RK, Soluti A. Effectiveness of various medications on postoperative pain following root canal obturation. J Endod. 1994; 20(9):427-31.

24.Gallatin E, Reader A, Nist R, Beck M. Pain reduction in untreated irreversible pulpitis using an intraosseous injection of Depo-Medrol. J Endod. 2000; 26(11):633-8.

25. Jens Ove Andreasen S, Storgård Jensen VSL. The role of antibiotics in preventing healing complications after traumatic dental injuries: a literature review. Endod Topics. 2006; 14(1):80-92.

26. Baker GR, Mitchell DF. Topical antibiotic treatment of infected dental pulps of monkeys. J Dent Res. 1969; 48(3):351-5.

27. Stewart PS, Costerton JW. Antibiotic resistance of bacteria in biofilms. Lancet. 2001; 358(9276):135-8.

28. Yingling NM, Byrne BE, 
Hartwell GR. Antibiotic use by members of the American Association of Endodontists in the year 2000: report of a national survey. J Endod. 2002; 28(5):396-404.

29. Hamid A, Uematsu H, Sato N, Kota K, Iwaku M, Hoshino E. Inhibitory effects of metronidazole on anaerobic metabolism of phenylalanine and leucine by Peptostreptococcus anaerobius. J Antimicrob
Chemother. 1997; 39(2):129-34. 30.Mainjot A, D'Hoore W, Vanheusden A, Van Nieuwenhuysen JP. Antibiotic prescribing in dental practice in Belgium. Int Endod J. 2009; 42(12):1112-7.

31. Garcez AS, Nuñez SC, Hamblin MR, Ribeiro MS. Antimicrobial effects of photodynamic therapy on patients with necrotic pulps and periapical lesion. J Endod. 2008; 34(2):138-42.
32.Fouad AF. Are antibiotics effective for endodontic pain? An evidence-based review. Endod Topics. 2002; 3(1):52-66.

33.Estrella C. Ciencia endodóntica.1a ed. Sao Paulo: Editorial artes medicas; 2005.

34. Altinsel HH, Ramnarine KC. Antibiotics in operative procedures and endodontics; in vitro studies. J Dent Res. 1956; 35(6):914-5. 